\title{
ARTICLE \\ Molecular analysis of the PAX6 gene for aniridia and congenital cataracts in Tunisian families
}

\author{
Manèl Chograni ${ }^{1}$, Kaouther Derouiche ${ }^{1}$, Myriam Chaabouni ${ }^{1}$, Imen Lariani ${ }^{1}$ and Habiba Chaabouni Bouhamed ${ }^{1,2}$
}

The aim of this study was to identify the genetic defect that is responsible for aniridia and congenital cataracts in two Tunisian families. Sequencing of the PAX6 gene in family F1 detected a novel c.265C $>$ T transition in exon 6 . In family F2, the previously described c.718C $>$ T mutation in PAX6 was detected in the four affected members. This study adds new mutation to those previously reported in PAX6, providing further evidence for the genetic and phenotypic heterogeneity in individuals with aniridia ocular malformations.

Human Genome Variation (2014) 1, 14008; doi:10.1038/hgv.2014.8; published online 4 September 2014

\section{INTRODUCTION}

Aniridia (AN2: OMIM 106210) is a panocular genetic disorder that is manifested by alterations in the structure and function of the eye, including a variable degree of iris hypoplasia and several other ocular features such as cataracts, glaucoma, corneal opacity, foveal hypoplasia and nystagmus. ${ }^{1}$ Genetically, aniridia is the first human malformation to be recognized as stemming from an alteration in a paired box homeotic gene. ${ }^{2}$ The only known gene for aniridia, PAX6, was cloned from chromosome $11 \mathrm{p} 13$, and, to date, no other genetic loci have been found to be associated with aniridia. ${ }^{3}$ In this study, we present the clinical and molecular genetic evaluations performed on two unrelated Tunisian families with aniridia and congenital cataracts.

\section{MATERIALS AND METHODS}

Two unrelated non-consanguineous Tunisian families were referred to the Department of Congenital and Hereditary Disorders at Charles Nicolle Hospital in Tunis, Tunisia, because multiple family members were affected with autosomal dominant aniridia associated with congenital cataracts (Figure 1). The clinical diagnosis was confirmed by ophthalmologic examination, including visual acuity, slit-lamp examination, gonioscopy, optical coherence tomography and a history of cataract extraction (if applicable). According to the classification of aniridia phenotypes, ${ }^{4}$ six of the seven affected patients were categorized as iris 6 (complete aniridia). The best-corrected visual acuity ranged from $1 / 10$ to $1.5 / 10$. The six affected patients had congenital nystagmus and congenital bilateral cataracts. The seventh patient, $\|_{8}$, who belonged to family $F 2$, had a unilateral cataract of the right eye.

Two patients, $\|_{8}$ (from F1) and $\|_{8}$ (from F2), had undergone cataract extraction. We noted that optical coherence tomography (OCT) demonstrated the presence of foveal hypoplasia in the brother $\mathrm{III}_{11}$ and the sister $\mathrm{III}_{12}$ from family $\mathrm{F} 1$, whose mother showed corneal dystrophy. All seven affected patients from the two families had normal muscle tone and normal signs on gonioscopy. However, most ophthalmologic features were not established for patient $\mathrm{III}_{14}$, who belonged to family F2, because of poor cooperation. Additional patient features are indicated in Table 1.

The study was performed in the Laboratory of Human Genetics, Faculty of Medicine of Tunis, Tunisia, in accordance with the declaration of Helsinki; the ethics committee of Charles Nicolle Hospital in Tunis gave approval for this study. Informed consent was obtained from all participants. One hundred unrelated subjects, with no features of ocular anomalies, were recruited as controls. Genomic DNA of the affected and unaffected members from the two studied families was extracted from peripheral blood leukocytes using a standard proteinase-K protocol.

All 14 exons and intron-exon junctions of the PAX6 gene were amplified from genomic DNA by polymerase chain reaction (PCR) using primers chosen by Primer3 (Primer3-web/hldocs/inpat-040.htm). The gene sequence was retrieved from the Ensembl database ENST00000241001. The amplification reactions were performed in an automated thermal cycle GeneAmp PCR System 9700 (Applied Biosystems, Foster City, CA, USA). The amplified products were purified (Zymo Research DNA Clean \& Concentrator-25 Kit, Irvine, CA, USA) and sequenced (Big Dye Terminator Cycle Sequencing Ready Reaction; DNA Sequencing Kit; ABI PRISM 3130) in the forward and reverse directions. Sequencing results were visualized, and the data were analyzed using the Sequencing Analysis 5.2 and SeqScape software (Applied Biosystems). Protein sequences among eight different species were aligned using the UCSC Genome Browser (http://genome. ucsc.edu/). The SMART site (Simple Modular Architecture Research Tool: http://smart.embl-heidelberg.de/) was used to compare the sequence of a normal protein with a mutated one.

\section{RESULTS}

By direct sequencing of the coding and flanking regions of PAX6, we identified a novel nonsense mutation (c.265C > T) in family F1 that was detected in exon 6 of the three affected members. The heterozygous mutation resulted in the substitution of a highly conserved glutamine codon for a termination codon (p.Q89X) leading to a truncated protein. The $c .265 \mathrm{C}>\mathrm{T}$ mutation was not detected in the unaffected father $\left(\mathrm{II}_{7}\right)$ or in any of the 100 control individuals from the same ethnic background, supporting the idea that this novel variation is a disease-causing mutation that segregates with the studied phenotype in family F1.

For the four affected individuals belonging to family F2, we detected a heterozygous substitution (c.718C $>$ T) in exon 9 of the PAX6 gene leading to the replacement of an arginine codon for a termination codon (p.R240X). This nonsense mutation, which generates a truncated protein, has previously been reported ${ }^{5-7}$ in patients with aniridia from different countries.

The sequence alignment analysis for the novel nonsense mutation, c. $265 \mathrm{C}>\mathrm{T}$, identified in family F1 showed that Gln89 
of the human PAX6 protein (Homo sapiens, NP_000271.1) was highly conserved in various species, including Pan troglodytes, Macaca mulatta, Mus musculus, Cavia porcellus, Loxodonta africana, Monodelphis domestica, Gallus gallus and Danio rerio.

A SMART analysis showed that the p.Q89X mutation was located at the DNA-binding paired domain of the PAX6 protein, which generated a truncated protein with 88 amino acids and containing only a non-functional paired domain (PD).

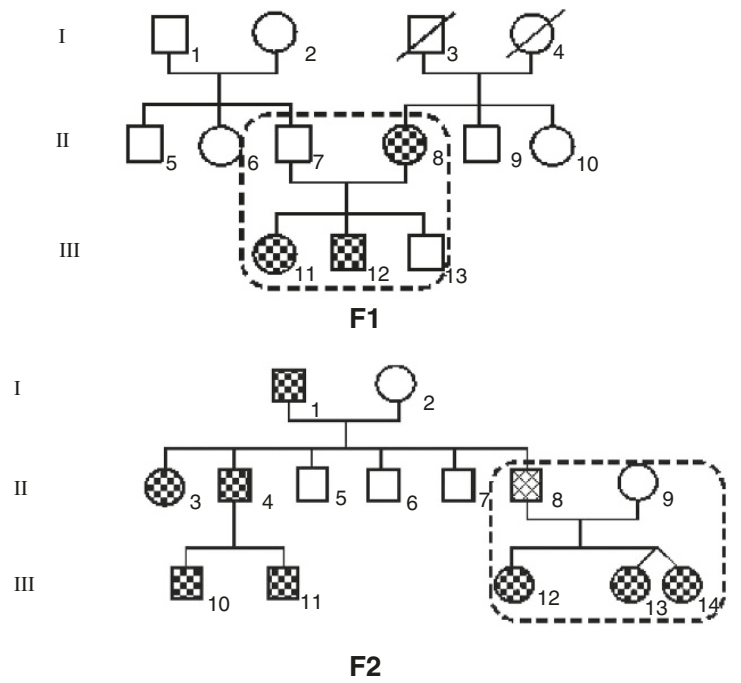

Total congenital aniridia + Congenital bilateral cataract
$\otimes$ Partial congenital aniridia + Congenital unilateral cataract

Figure 1. Pedigrees of the two screened families showing autosomal dominant inheritance of aniridia associated with cataracts.

\section{DISCUSSION}

Aniridia is most often caused by intragenic mutations in the PAX6 gene. ${ }^{7}$ Most PAX6 mutations reported so far lead to the truncation of encoded proteins. In the present study, the two identified PAX6 mutations are nonsense mutations. Each mutation is a single basepair substitution that generates a stop codon. The first one, c.265C $>\mathrm{T}$, is a novel mutation detected in a Tunisian family (F1) with aniridia and congenital cataracts. This mutation leads to a truncated PAX6 protein via the substitution of a highly conserved amino acid (GIn) for a termination codon (p.Q89X). The p.Q89X was not detected in 100 ethnically matched, healthy individuals and had not been previously reported according to the Human PAX6 mutation database (http://www.hgu.mrc.ac.uk/Softdata/ PAX6/) and LOVD (MRC Human Genetics Unit LOVD at MRC IGMM, Paired box gene 6). This finding confirms that the sequence change is a disease-causing, co-segregating mutation that affects the DNA-binding paired domain of the PAX6 protein. This point mutation is an $\mathrm{N}$-terminal mutation leading to a severe phenotype in the affected members of this family.

The sequence alignment analysis shows that Q89 is highly conserved in vertebrates. Consequently, the c.265C $>$ T mutation affecting the PAX6's PD is inclined to cause PAX6 haploinsufficiency through a loss-of-function mutation and produced complete congenital aniridia and congenital cataracts in the mother of family F1 and her two children. Structurally, PAX6 is composed of 422 amino acids, with 124 amino acids comprising the PD. The novel substitution of the glutamine codon for a stop codon at position 89 of the protein PAX6 generates a truncated protein composed only of an aberrant PD of 88 amino acids. Consequently, a haploinsufficiency of the PAX6 protein is generated, in which the mutated PAX6 protein does not have any transcriptional activity, and the remaining single normal copy of PAX6 does not produce a functional threshold level of biologically active PAX6 protein sufficient to initiate the transcription of its target genes.

The father of family F2 presented with partial aniridia associated with a unilateral congenital cataract, while his three children were diagnosed with complete aniridia and bilateral congenital

Table 1. The clinical features of aniridia patients in two unrelated Tunisian families

\begin{tabular}{|c|c|c|c|c|c|c|c|}
\hline \multirow{2}{*}{$\begin{array}{l}\text { Families } \\
\text { Patients }\end{array}$} & \multicolumn{3}{|c|}{$F 1$} & \multicolumn{4}{|c|}{ F2 } \\
\hline & $\|_{8}$ & $I I I_{11}$ & $I I I_{12}$ & $\|_{8}$ & $I I I_{12}$ & $I I I_{13}$ & $I I I_{14}$ \\
\hline Gender & $\mathrm{F}$ & $\mathrm{F}$ & M & $M$ & $\mathrm{~F}$ & $\mathrm{~F}$ & $\mathrm{~F}$ \\
\hline Age (years) & 56 & 11 & 14 & 39 & 11 & 9 & 9 \\
\hline \multicolumn{8}{|l|}{$C V A$} \\
\hline $\mathrm{R}$ & $1 / 20$ & $1 / 10$ & $1 / 10$ & $1 / 10$ & $1 / 10$ & $1 / 10$ & NA \\
\hline L & $1 / 20$ & $1.5 / 10$ & $1.5 / 10$ & $1.5 / 10$ & $1 / 10$ & $1 / 10$ & NA \\
\hline Nystagmus & Congenital & Congenital & Congenital & Congenital & Congenital & Congenital & Congenital \\
\hline Cataract & $\begin{array}{l}\text { Congenital } \\
\text { bilateral }\end{array}$ & $\begin{array}{l}\text { Congenital } \\
\text { bilateral } \\
\text { subcapsular type }\end{array}$ & $\begin{array}{l}\text { Congenital } \\
\text { bilateral } \\
\text { subcapsular type }\end{array}$ & $\begin{array}{l}\text { Congenial unilateral } \\
\text { nuclear and cortical } \\
\text { progressive type (R) }\end{array}$ & $\begin{array}{l}\text { Congenital } \\
\text { bilateral anterior } \\
\text { pyramidal type }\end{array}$ & $\begin{array}{l}\text { Congenital } \\
\text { bilateral }\end{array}$ & $\begin{array}{l}\text { Congenital } \\
\text { bilateral }\end{array}$ \\
\hline Aniridia & Complete & Complete & Complete & Partial (L) & Complete & Complete & Complete \\
\hline Muscle tone & $\mathrm{N}$ & $\mathrm{N}$ & $\mathrm{N}$ & $\mathrm{N}$ & $\mathrm{N}$ & $\mathrm{N}$ & NA \\
\hline OCT & $\mathrm{N}$ & $\begin{array}{l}\text { Foveal } \\
\text { hypoplasia }\end{array}$ & $\begin{array}{l}\text { Foveal } \\
\text { hypoplasia }\end{array}$ & $\mathrm{N}$ & $\mathrm{N}$ & $\mathrm{N}$ & NA \\
\hline Gonioscopy & $\mathrm{N}$ & $\mathrm{N}$ & $\mathrm{N}$ & $\mathrm{N}$ & $\mathrm{N}$ & $\mathrm{N}$ & NA \\
\hline Other features & $\begin{array}{l}\text { Corneal } \\
\text { dystrophy }\end{array}$ & - & - & $\begin{array}{l}\text { Implant of the } \\
\text { posterior chamber } \\
\text { R: crystalline lens } \\
\text { and iris coloboma }\end{array}$ & $\begin{array}{l}\text { Remnants of } \\
\text { pupillary } \\
\text { membrane }\end{array}$ & $\begin{array}{l}\text { L: decrease in } \\
\text { foveal reflection } \\
\text { R: sclerocornea }\end{array}$ & - \\
\hline
\end{tabular}

Abbreviations: CVA, corrected visual acuity; F, female; L, left eye; M, male; OCT, optical coherence tomography; N, normal; NA, not available; R, right eye. 
cataracts with other variable ocular anomalies. We identified the previously described c.718C $>T$ ( $p . R 240 X)$ nonsense mutation in exon 9 of PAX6 gene in this family.

The p.R240X, which involves CpG dinucleotides, is among the most common nonsense mutation in $P A X 6^{7-9}$ and was reported to be pathogenic. It affects the homeodomain of the protein in that the premature insertion of a stop codon is predicted to result in nonsense-mediated decay and, consequently, a functionally null allele. $^{10,11}$ Previously, this point mutation was found in at least 31 patients worldwide, including the familial and sporadic cases reported in the Human PAX6 Mutation Database; 26 of the patients have isolated aniridia, and the remaining 5 have associated ocular anomalies (4 with cataracts).

PAX6 mutations have been detected in individuals with various types of ocular anomalies. ${ }^{12}$ The father, $\|_{8}$, from family $F 2$, presented with partial aniridia of the left eye $\left(<180^{\circ}\right)$ and a congenital cataract of nuclear and cortical progressive type in the right eye. Previously, this particular phenotype has not been reported to be associated with p.R240X. This phenotype could be explained by the wide expression of PAX6 gene in the developing eye and its involvement in ocular morphogenesis, notably in lens development. This report confirms the phenomenon of variable phenotypes occurring within a family and indicates that factors other than the mutated PAX6 protein may contribute to the complexity of anterior segment phenotypes. ${ }^{8,9}$

In summary, we identified a novel nonsense mutation (p.Q89X) in a Tunisian family with aniridia and congenital cataracts. Additionally, we highlighted the predicted pathogenic effect of the reported nonsense mutation, p.R240X, in a second Tunisian family with aniridia, congenital cataracts and variable ocular anomalies. These two mutations lead to truncated proteins and added to the large spectrum of nonsense mutations associated with aniridia.

\section{COMPETING INTERESTS}

The authors declare no conflict of interest.

\section{ACKNOWLEDGEMENTS}

We thank all the patients and their family members for participating in the project. This study was supported by the Tunisian Ministry of Higher Education and Scientific
Research (Laboratory of Human Genetics, Faculté de Médicine de Tunis and Congenital and Hereditary service of Charles Nicolle's Hospital).

\section{REFERENCES}

1 Axton R, Hanson I, Danes S, Sellar G, van Heyningen V, Prosser J. The incidence of PAX6 mutation in patients with simple aniridia: an evaluation of mutation detection in 12 cases. J Med Genet 1997; 34: 279-286.

2 Chien YH, Huang HP, Hwu WL, Chien YH, Chang TC, Lee NC. Eye anomalies and neurological manifestations in patients with PAX6 mutations. Mol Vis 2009; 15: 2139-2145.

3 Dohrmann C, Gruss P, Lemaire L. Pax genes and the differentiation of hormoneproducing endocrine cells in the pancreas. Mech Dev 2000; 92: 47-54.

4 Glaser T, David SW, Jiexing C. PAX6 gene mutations in Aniridia. Mol Genet Ocular Dis 1995, 51-82.

5 Epstein JA, Glaser T, Cai J, Jepeal L, Walton DS, Maas RL. Two independent and interactive DNA-binding subdomains of the Pax6 paired domain are regulated by alternative splicing. Genes Dev 1994; 8: 2022-2034.

6 Glaser T, Walton DS, Maas RL. Genomic structure, evolutionary conservation and aniridia mutations in the human PAX6 gene. Nat Genet 1992; 2: 232-239.

7 Gronskov K, Rosenberg T, Sand A, Brøndum-Nielsen K. Mutational analysis of PAX6: 16 novel mutations including 5 missense mutations with a mild aniridia phenotype. Eur J Hum Genet 1999; 7: 274-286.

8 Wilson DS, Guenther B, Desplan C, Kuriyan J. High resolution crystal structure of a paired (Pax) class cooperative homeodomain dimer on DNA. Cell 1995; 82: 709-719.

9 Wolf MT, Lorenz B, Winterpacht A, Sellar G, van Heyningen V, Prosser J. Ten novel mutations found in aniridia. Hum Mutat 1998; 12: 304-313.

10 Robinson DO, Howarth RJ, Williamson KA, van Heyningen V, Beal SJ, Crolla JA. Genetic analysis of chromosome $11 \mathrm{p} 13$ and the PAX6 gene in a series of 125 cases referred with aniridia. Am J Med Genet A 2008; 146A: 558-569.

11 Shaw MW, Falls HF, Neel JV. Congenital aniridia. Am J Hum Genet 1960; 12: 389-415.

12 Ton CC, Hirvonen H, Miwa H, Weil MM, Monaghan P, Jordan T et al. Positional cloning and characterization of a paired box- and homeobox-containing gene from the aniridia region. Cell 1991; 67: 1059-1074.

(c) (1) $\odot$ This work is licensed under a Creative Commons Attributionother third party material in this article are included in the article's Creative Commons license, unless indicated otherwise in the credit line; if the material is not included under the Creative Commons license, users will need to obtain permission from the license holder to reproduce the material. To view a copy of this license, visit http://creativecommons.org/licenses/by-nc-nd/3.0/ 